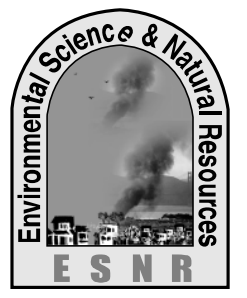

J. Environ. Sci. \& Natural Resources, 6(1): 227 - 232, 2013

ISSN 1999-7361

\title{
Ecology of the Slug, Girasia crocea (Godwin-Austen) (Stylommatophora : Ariophantidae)
}

\author{
M. M. S. Bhuiyan ${ }^{1}$, M. R. Rahman ${ }^{2}$, M. S. Jahan ${ }^{3}$ and ${ }^{4}$ M. Haque \\ ${ }^{1}$ Barura Shahid Smriti Government College, Comilla \\ ${ }^{2,3}$ Institute of Environmental Science, University of Rajshahi, Rajshahi- 6205, Bangladesh \\ ${ }^{4}$ Dr. Khandaker Mosharraf Hossain College, Daudkandi, Comilla, Bangladesh
}

\begin{abstract}
Slug Girasia crocea (Godwin-Austen) is an herbivore, feeds on soft twigs or leaves of plants. The slug G. crocea are active for period of March-November. They use to overcome winter month (December-February) through hibernation. Sometimes they were seen to winter morning. In nature, they have a wide range of food acceptability. The feeding and foraging activities are confined to night ours. In nature, breeding period extends from March to November. The egg laying and other breeding activities are maintained at an equal temperature during the whole active period. In laboratory, they thrived well on Amranthus sp. And Spinacea sp., while temperature. They attained adult at the age of 196 days to 201 days. They lay eggs lay in cluster. The eggs are round in shape and white in colour. Individual slugs on an average, added $9.5 \mathrm{~mm}, 2.5 \mathrm{~mm}$ and $40 \mathrm{mg} ; 13.5 \mathrm{~mm}, 3.5 \mathrm{~mm}$ and $40 \mathrm{mg}$; $17 \mathrm{~mm}, 5 \mathrm{~mm}$ and 50mg; $24 \mathrm{~mm}, 5 \mathrm{~mm}$ and $60 \mathrm{mg} ; 35.5 \mathrm{~mm}, 6 \mathrm{~mm}$ and $485 \mathrm{mg} ; 52 \mathrm{~mm}, 10 \mathrm{~mm}$ and $1190 \mathrm{mg} ; 65 \mathrm{~mm}, 8.5 \mathrm{and} 1114 \mathrm{mg}$; $65 \mathrm{~mm}, 9.5 \mathrm{~mm}$ and $1117 \mathrm{mg}$ and $57 \mathrm{~mm}, 10 \mathrm{~mm}$ and $1134 \mathrm{mg}$ to their body length, body width and body weight respectively at temperature of $26-31.5^{\circ} \mathrm{C}$ during the study period. On an average an egg was measured $3.85 \mathrm{~mm}$ in diameter.
\end{abstract}

Keywords: Breeding Biology, Ecology, Girasia crocea, Growth rate, Slug, Temperatures

\section{Introduction}

Slug and snails causing damage to economic plants have drawn the attention of a number of workers (Hyman, 1967; Runham and Hunter, 1970; Godan, 1983). Besides these, numerous paper have been published on the other members of the pulmonate snails, viz., Achatina fulica, $M$. indica and $M$. sequax (Mead, 1950, Ghose, 1959, 1960, 1963; Hodasi, 1962, 1975, 1979; Raut, 1979, 1981; Raut and Ghose, 1982, 1983a, 1983b, 1984). But no records are yet available on the natural history of the species Girasia crocea (Godwin-Austen). These species are an agro horticulture slug pest in Bangladesh and neighboring countries. The information on their biology and ecology is still wanting. In the present study an attempt has been made to study their ecology.

\section{Material and Methods}

Observation on the ecology of the Slug Girasia crocea have been made from Bangladesh Academy for Rural Development (BARD) forest, located in the Comilla district, Bangladesh. During the summer (March-April) the temperature ranges $30-33.2^{\circ} \mathrm{C}$, while in winter (December-January) $12.1-27.6^{\circ} \mathrm{C}$. In other month temperature ranges from $29-32^{\circ} \mathrm{C}$.

Observations under laboratory conditions have been made at the Institute of Environmental Science (IES) Laboratory University of Rajshahi. For the laboratory studies two clutch of eggs consisting of 35 and 38 eggs respectively collected from BARD forest, located in the Comilla district. The eggs were released in two wooden $50 \times 50 \times 10 \mathrm{~cm}$ each in size. The boxes were provided with loose, moist soil up to $5 \mathrm{~cm}$ of its height. The upper side of the box was protected with a piece of nylon net $(0.1 \mathrm{~mm}$ mesh). Throughout the period of study $40-45 \%$ soil was maintained through regular water spraying. After hatching the leaves of Amaranth gangeticus and Spinacea oleracea were supplied regularly as their food. The unused food materials and the faecal matters were removed daily from the boxes with a view to maintain a strict hygienic condition. The soils were also change 15days interval to avoid any kind of infection.

Through regular observations fortnightly length, width and weight were studied. Incubation and hatching percentage were calculated from the emergence of juvenile snails from the eggs. The experiment was continued until the entire slug died.

For the study of desired traits depending on the availability of hatching ( 0 day old snails) two batches of wooden box ( 5 for each species) set up. The slugs considered for experiment carefully until the last individual of each batch died. Randomly 5 species from each batch were consider for measurement of the length, width and weight with the help of divider and electrical balance (model, no.HF-200h, Max-210, $\mathrm{d}=0.001$ ) after 15 days. The experimented was started July 2007 and terminated on 30 September 2008.

\section{Result and Discussion}

\section{Breeding Biology in the Natural Habitat}

The slug G. crocea are active for period of MarchNovember. They are nocturnal. In day time they were seen under stones, bricks and dead logs etc. With the approach of darkness these creature were seen to come out of their hiding places. These slugs have wide ranges of food plant acceptability both cultivated ant wild variety. The Slugs laid eggs in 
cluster. Though the fresh laid eggs are found in cluster and the developed eggs are always seen in isolated condition. The eggs are round in shape, white in colour and transparent in early age. The eggs size from $3.1-4.6 \mathrm{~mm}$. With the advent of winter the slugs inter to protective place usually under the stones, bricks and wooden logs etc. to the tide over the colder period (from December to February) every year.

\section{Breeding Biology in the Simultaneous Laboratory} Condition (Table 1 - 13)

In Box one, the 48 eggs, 35 hatched on 17 March, 2008, while the remaining 13 did not hatched. In Box (Terrarium) two, 73 eggs, 38 hatched on same date as Box 1.17 March, 2008, while the remaining 35did not hatched.

The newly hatched slugs measured 6.5-11.5 (average $\mathrm{mm}$ ) $\mathrm{mm}, 2.5-3.5$ (average $3.00 \mathrm{~mm}$ ) $\mathrm{mm}$ and 3040mg (average $35 \mathrm{mg}$ ) in body length, width and weight respectively. They fed mostly Amaranthus $s p$. and Spinacea sp.

Again, after 15 days, in Box 1 and 2 body length, width, weight and mortality rate were measured. Later, on $20^{\text {th }}$ April, $5^{\text {th }}$ May, 20 ${ }^{\text {th }}$ May, 7 July, 23 July, $24^{\text {th }}$ August, $9^{\text {th }}$ September and $25^{\text {th }}$ September body length, width, weight and mortality rate were measured.Due to unavoidable circumstance body length, width, weight and mortality rate were not measured June 2008.

On September 25, 2008, two slugs were alive. Their body length, width and weight are given table 10 . Of the two slugs, one died on September 25, 2008 at the age of 196 days and other individual died on 30 September 30 at the age of 201 days. The eggs hatched between $26-31.5^{\circ} \mathrm{C}$ temperatures. A total of 73 eggs hatched out 105 , giving $69.52 \%$ successful hatching.

Table 1. Length, width and weight of $G$. crocea (0 day old)

\begin{tabular}{cccc}
\hline Sample no. & Length $(\mathrm{mm})$ & Width $(\mathrm{mm})$ & Weight $(\mathrm{gm})$ \\
\hline Juvenile 1 & 9.5 & 2.5 & 40.00 \\
Juvenile 2 & 9.00 & 3.00 & 38.00 \\
Juvenile 3 & 6.5 & 3.5 & 30. \\
Juvenile 4 & 11.5 & 3.00 & 46.00 \\
Juvenile 5 & 10.5 & 3.5 & 45.00 \\
\hline
\end{tabular}

Table 2. Length, width and weight of G. crocea (15 days old) (Box 1)

\begin{tabular}{ccccc}
\hline Sample no. & Length $(\mathrm{mm})$ & Width $(\mathrm{mm})$ & Weight $(\mathrm{gm})$ & Mortality number \\
\hline Juvenile 1 & 15.5 & 3.5 & 48.00 & 15 juvenile died \\
Juvenile 2 & 14.00 & 3 & 40.00 & out of 35 slugs \\
Juvenile 3 & 13.5 & 3.00 & 40.00 & \\
Juvenile 4 & 13.00 & 3.5 & 40.00 & \\
Juvenile 5 & 15.5 & 3.5 & 48.00 & \\
\hline
\end{tabular}

Table 3. Length, width and weight of $G$. crocea (15 days old) (Box 2)

\begin{tabular}{ccccc}
\hline Sample no. & Length $(\mathrm{mm})$ & Width $(\mathrm{mm})$ & Weight $(\mathrm{mg})$ & Mortality number \\
\hline Juvenile 1 & 12.00 & 4.00 & 36.00 & \\
Juvenile 2 & 13.00 & 4.00 & 40.00 & 4 juvenile died out \\
Juvenile 3 & 11.00 & 2.00 & 36.00 & of 38 slugs \\
Juvenile 4 & 14.00 & 4.00 & 48.00 & \\
Juvenile 5 & 10.00 & 3.25 & 36.00 & \\
\hline
\end{tabular}

Table 4. Length, width and weight of G. crocea (30 days old) (Box 1)

\begin{tabular}{ccccc}
\hline Sample no. & Length $(\mathrm{mm})$ & Width $(\mathrm{mm})$ & Weight $(\mathrm{mg})$ & Mortality number \\
\hline Juvenile 1 & 17.00 & 5.00 & 50.00 & 10 juvenile died \\
Juvenile 2 & 18.00 & 6.00 & 90.00 & out of 20 slugs \\
Juvenile 3 & 18.00 & 6.5 & 90.00 & \\
Juvenile 4 & 12.1 & 3.00 & 60.00 & \\
Juvenile 5 & 15.00 & 4.00 & 95.00 & \\
\hline
\end{tabular}




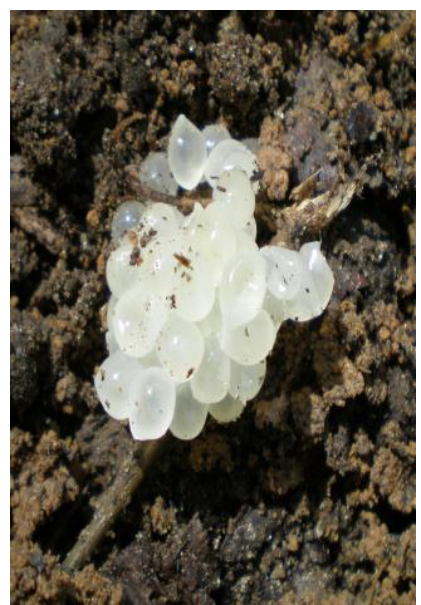

Plate A. Egg cluster

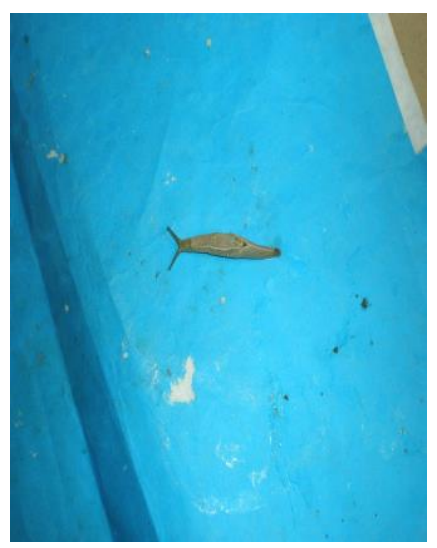

Plate D. 30 days old aged

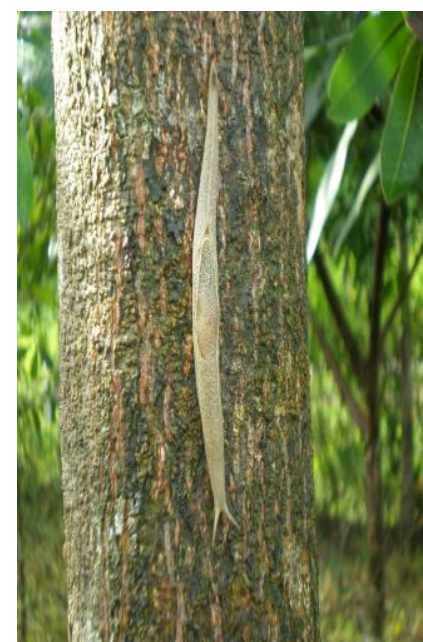

Plate G. 108 days old aged

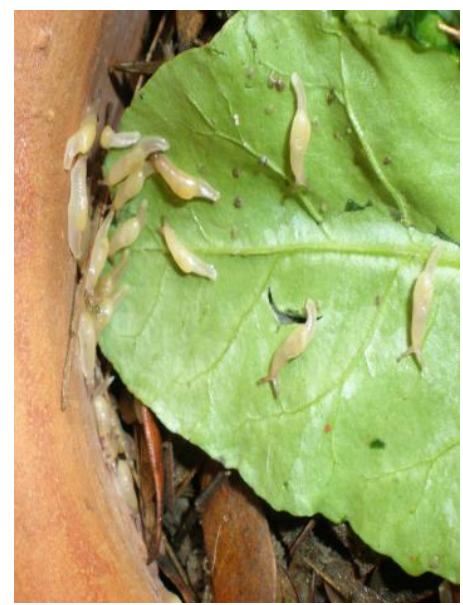

Plate B. Newly hatched (0 Day)

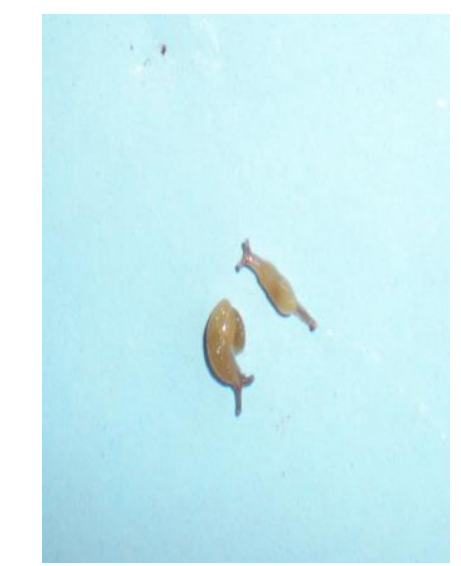

Plate E. 45 days old aged

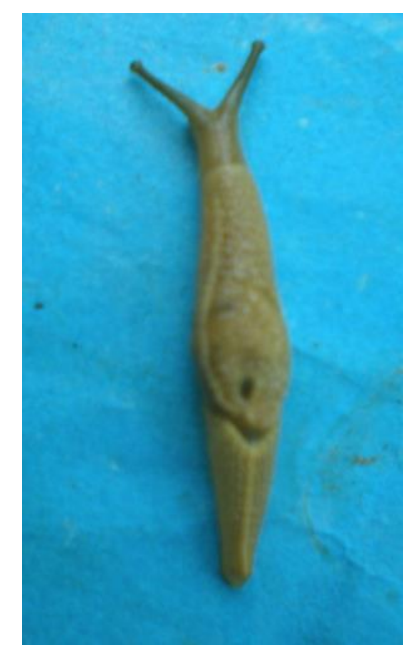

Plate H. 153 days old aged

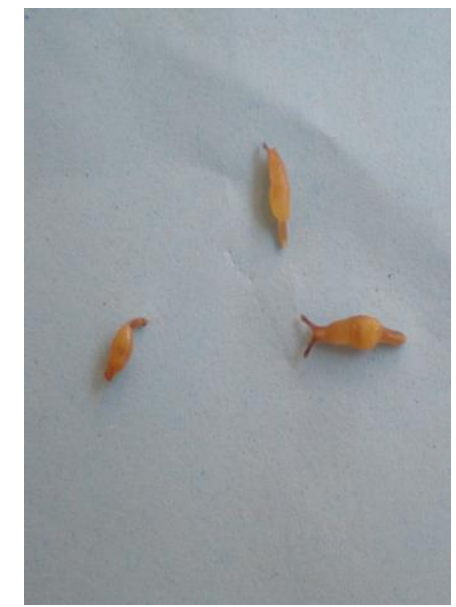

Plate C. 15 days old aged

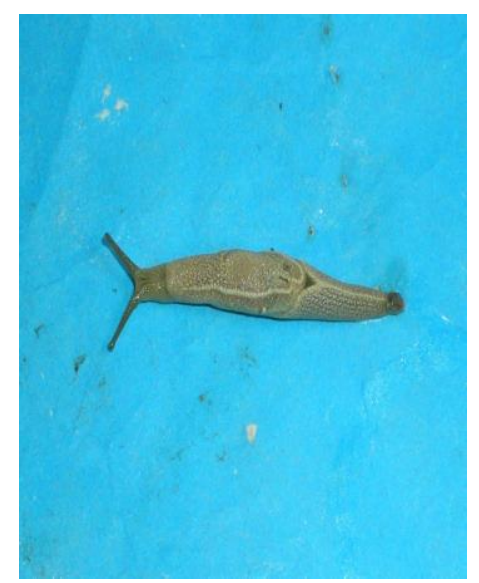

Plate F. 60 days old aged

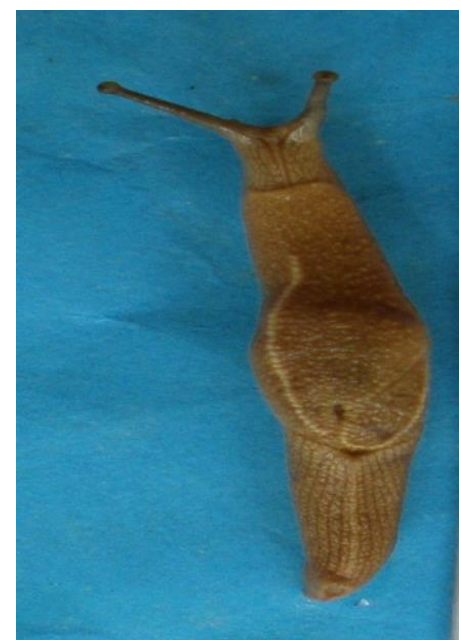

Plate I. 183 days old aged

Table 5. Length, width and weight of G. crocea (30 days old) (Box 2)

\begin{tabular}{cclll}
\hline Sample no. & Length $(\mathrm{mm})$ & Width $(\mathrm{mm})$ & Weight $(\mathrm{mg})$ & Mortality number \\
\hline 1 & 12.00 & 6.00 & 121.00 & 35 juvenile died \\
2 & 12.00 & 5.00 & 90.00 & out of 38 slugs \\
3 & 7.50 & 4.00 & 50.00 & \\
\hline
\end{tabular}


Table 6. Length, width and weight of G. crocea (45 days old) (Box 1)

\begin{tabular}{rrlll}
\hline Sample no. & Length $(\mathrm{mm})$ & Width $(\mathrm{mm})$ & Weight $(\mathrm{mg})$ & Mortality number \\
\hline 1 & 24.00 & 5.00 & 60.00 & 2 juvenile died out \\
2 & 24.5 & 4.5 & 100.00 & of 10 slugs \\
3 & 26.00 & 5.00 & 150.00 & \\
4 & 27.00 & 5.00 & 130.00 & \\
5 & 22.00 & 4.00 & 50.00 & \\
\hline
\end{tabular}

Table 7. Length, width and weight of G. crocea (45 days old) (Box 2)

\begin{tabular}{rrlll}
\hline Sample no. & Length $(\mathrm{mm})$ & Width $(\mathrm{mm})$ & Weight $(\mathrm{mg})$ & Mortality number \\
1 & 26.00 & 6.00 & 210.00 & 2 juvenile died out \\
2 & 27.000 & 4.5 & 130.00 & of 10 slugs \\
3 & 17.00 & 4.00 & & \\
\hline
\end{tabular}

Table 8. Length, width and weight of G. crocea (60 days old)

\begin{tabular}{llll}
\hline Sample no. & Length $(\mathrm{mm})$ & Width $(\mathrm{mm})$ & Weight $(\mathrm{mg})$ \\
\hline 1 & 27.00 & 7.00 & 70.00 \\
2 & 29.00 & 6.00 & 84.00 \\
3 & 22.00 & 6.00 & 72.00 \\
4 & 21.00 & 5.00 & 60.00 \\
5 & 20.00 & 5.00 & 60.00 \\
\hline
\end{tabular}

Table 9. Length, width and weight of G. crocea (108days old)

\begin{tabular}{llll}
\hline Sample no. & Length $(\mathrm{mm})$ & Width $(\mathrm{mm})$ & Weight $(\mathrm{mg})$ \\
\hline 1 & 35.50 & 6.00 & 485.00 \\
2 & 35.00 & 7.00 & 809.00 \\
3 & 43.00 & 8.00 & 910.00 \\
\hline
\end{tabular}

Table 10. Length, width and weight of G. crocea (123 days old)

\begin{tabular}{llll}
\hline Sample no. & Length $(\mathrm{mm})$ & Width $(\mathrm{mm})$ & Weight $(\mathrm{mg})$ \\
\hline 1 & 52.00 & 10.00 & 1190.00 \\
2 & 44.00 & 8.00 & 1111.00 \\
3 & 36.00 & 7.00 & 490.00 \\
\hline
\end{tabular}

Table 11. Length, width and weight of G. crocea (153 days old)

\begin{tabular}{llll}
\hline Sample no. & Length $(\mathrm{mm})$ & Width $(\mathrm{mm})$ & Weight $(\mathrm{mg})$ \\
\hline 1 & 65.00 & 8.5 & 1114.00 \\
2 & 50.00 & 8.5 & 1117.26 \\
\hline
\end{tabular}

Table 12. Length, width and weight of G. crocea (168 days old)

\begin{tabular}{llll}
\hline Sample no. & Length $(\mathrm{mm})$ & Width $(\mathrm{mm})$ & Weight $(\mathrm{mg})$ \\
\hline 1 & 65.00 & 9.5 & 1117.00 \\
2 & 56.00 & 9.00 & 1152.00 \\
\hline
\end{tabular}

Table 13. Length, width and weight of G. crocea (183 days old)

\begin{tabular}{llll}
\hline Sample no. & Length $(\mathrm{mm})$ & Width $(\mathrm{mm})$ & Weight $(\mathrm{mg})$ \\
\hline 1 & 49.00 & 11.00 & 1104.00 \\
2 & 57.00 & 10.00 & 1134.00 \\
\hline
\end{tabular}


G. crocea are hermaphrodite. In nature they become adult at the age of 6 months. The result of field and laboratory observations clearly indicate that the slugs are adapted to moderate temperature and they are confined to some district of North eastern region (Comilla, Habiganj, Maulvibzar, Sylhet districts), Eastern region (Chittagong and Chittagong Hill tracts) and Rajshahi of Bangladesh where average temperature prevails around $15-33.5^{\circ} \mathrm{C}$ and humidity $70-87 \%$ due to regular shower. Though the studies on the distribution of this slug species are not on record it is apparent that $G$. crocea have not close affinity with the slug occurring in cold countries. Further information on the distribution of this slug species is needed to determine the original home land of $G$. crocea and its pattern of distribution in the tropical countries.

While all other biological activities of $G$. crocea are more or less similar to Mariaella dussumeri (Raut et al., 1990) and other slug species studied so far (Runham and Hunter, 1970; Godan, 1983) egg nesting demand is special attention. A number of workers studied egg nesting behaviour of a number of pulmonates in different ecological conditions viz., Achatina fulica, M. indica (Ghose, 1959), Achatina fulica (Hodasi, 1975, 1979), M. tugurium and Cryptaustenia ovata (Saha and Roy, 1994). All of them stated that breeding seasons of the above snails species commence at the advent of monsoon and egg laying are preceded by making an egg chamber into which the eggs are deposited. In the present study it is clear that G. crocea are used to deposit eggs in clusters but deposition of eggs, completely separate from each other, though rare is also practice. In nature, end of the summer and advent of monsoon they starts laying eggs. It seems that the art of deposition of eggs by the slugs is very much related with the care of eggs laid.

The care of eggs not only involved with the protection of eggs from any kind of damage following displacement but saves the eggs from desiccation to ensure cent prevent hatchability. Besides, deposition of eggs inside the litters by G. crocea give added protection from enemies and desiccation. Like as $G$. crocea same kind of deposition of eggs was found in slug Mariaella dussumeri. In addition, the Slug Laevicaulis alte perhaps developed a unique divide to ensure cent percent hatching of eggs by depositing faecal pellets over the egg mass (Raut and Panigrahi, 1988).

The age of sexual maturity in pestiferous land snails varies. The age at which sexual maturity is reached possibly varies with the influence of environmental factors. Macrochlamys indica sexually mature by 130 days (Raut and Ghose, 1984). The growth rate of $M$. indica for a period of 57 weeks suggest that the attainment of reproductive age influence the process (Raut and Ghose, 1984). Slow growth rate following has also been reported by (Fromming, 1954). Ghose (1963) holds that the growth rate in Achatina fulica faster till the attainment of sexual maturity. The number of eggs per clutch, egg diameter, incubation period and hatchability of $M$. indica as 12-40, 3.0$3.5 \mathrm{~mm}, 10-17$ days and $96 \%$, were described by (Raut and Ghose, 1984). In M. tugurium and Cryptaustenia ovata, eggs per clutch and incubation period and hatchability were recorded per $100.88 \pm 10.96$ and $34.17 \pm 3.34,15$ to 26 days, 9 to 26 days $91.9 \%$ respectively. But during the present investigation were found as 48-57, 11-13 days and $69.52 \%$ respectively.

Some workers (Hodasi, 1979; Raut and Ghose, 1982) studied the life history, mortality rate and life table for land mollluscs. Raut and Ghose (1981) recorded $30-46 \%$ for $100-105$ days age group and $90-98.33 \%$ for 0-35 day's age groups as survival values of $M$. indica. They found the maximum and minimum mortality in 82-189 and 49-56 days age groups. Again, the overall expectation of life was maximum of 14.45 days for 0 day individuals and minimum was 0.50 days for 189 day. During the present experiment the maximum life span of G. crocea was recorded in laboratory condition as 196 -201 days respectively. All the individual of same lot died within $196-201$ days. In $G$. crocea maximum growth occurred 168 days and then it declined (Table 8). G. crocea is a vegetable pest.

\section{Acknowledgements}

The Authors wish to express their sincere thanks to Mr. Barura, Zoological Survey of India for identifying the species. With deep gratitude, to Professor S. K. Raut, Department of Zoology, University of Calcutta, India, for kind advice and provided some relevant papers.

\section{References}

Fromming, E. 1954. Biolgie der mittleuropaischen Sufwasserschnecken. Dunker and Humblot, Berlin. 313pp.

Ghose, K. C. 1959. Observation on the mating and oviposotion of two land Pulmonates, Achatina fulica, Bowdich and Macrochlamys indica Godwin-Austen. Journal of Bombay Natural History Society., 56: 183-187.

Ghose, K. C. 1960. Observation on the gametes, fertilization and gonodal activities of two land Pulmonates, Achatina fulica, Bowdich and Macrochlamys indica Godwin-Austen, 
Proceeding of the Zoological Society of Calcutta. 13: 91-96.

Ghose, K. C. 1963. The early stage of development in Achatina fulica, Bowdich (Mollusca :Gastropoda). Journal of Bombay Natural History Society, 60: 228-238.

Godan, D. 1983. Pest slugs and snails, SpringerVeriag, Berlin, Heidelberg, New York. pp.445.

Hodasi, J. K. M.1975. Preliminary studies on the feeding and burrowing habits of Achatina achatina. Ghana e Journal of Science, 13:91-96.

Hodasi, J. K. M. 1979. Life history studies of Achatina fulica. The Journal of Molluscan Studies, 45(3): 328-339.

Hyman, L .H. 1967. The Invertebrates, Volume VI (Mollusca 1). McGraw-Hill Book Company, New York, St.Louis, San Francisco, Toronto, Sydney. pp. 1-729.

Mead, A. R. 1950. Comparative genital anatomy of some African Achatinidae (Pulmonata), Bulletin of the Comparative Zoology, Harvard, 105: 219-291.

Mead, A. R. 1962. The Giant African Snail, Chicago, The University of Chicago Press.

Raut, S. K. and Ghose, K.C. 1983a. The role of noncrop plants in the protection of crop plants against the Pestiferous land snails, Achatina fulica Malac Rev. 16: 95-96.

Raut, S. K. and Ghose, K. C. 1983b. Food preference and feeding behaviour of Achatina fulica, Bowdich and Macrochlamys indica GodwinAusten. Records of the Zoological Survey of India, 80(3\&4): 421-439.
Raut, S. K. and Ghose, K. C. 1982. Viability of sperm in aestivating Achatina fulica, Bowdich and Macrochlamys indica Godwin-Austen. The Journal of Molluscan Studies, 48(1): 84-86.

Raut, S. K. and Ghose, K. C. 1984. Pestiferous land snails of India. Technical Monograph, No.11, Zoological Survey of India. pp.1-151.

Raut, S. K. and Panigrahi, A. 1988. Egg nesting in the garden slug Laevicaulis alte (Ferussac) (Gastropda: Soleolifera). Malac. Rev. 21:101-107.

Raut, S. K.; Panigrahi, A. and Samanta, S. 1990.Some Aspects of Bioecology of the Penisular Slug Mariaella dussumeieri (Gray), Pulmonata: Ariophantidae.

Raut, S. K.1979. Distribution and population of two land snails Achatina fulica, Bowdich and Macrochlamys indica Godwin-Austen. Bulletin of the Zoological Survey of India, 13: 91-96.

Raut, S. K. 1981. Impact of soil distribution of giant two land snails Achatina fulica, Bowdich , Progress in soil Biology and Ecology. UAS Technical Series, 37:79-84.

Runham, N. W. and Hunter, P. J. 1970. Terrestrial slugs. Hutchinson University Library. pp.1184.

Saha, T. C. and Roy, S. P. 1994. Egg nesting behaviour, clutch size and hatching of eggs of two hill pulmonates Macrochlamysu tugurium (Benson) and Cryptaustenia ovata (Blanford)(Mollusca: Gastropoda). Journal of Bengal Natural History Society New Series, 13(2): 15-22. 